\title{
Editorial
}

\section{Introduction to Pedagogical Linguistics}

\author{
Andreas Trotzke ${ }^{1,2} \&$ Tom Rankin ${ }^{3}$ \\ ${ }^{1}$ Universität Konstanz $\mid{ }^{2}$ Universitat Autònoma de Barcelona \\ ${ }^{3}$ Johannes Kepler Universität Linz
}

Linguistics comes in many flavors. Applied, cognitive, descriptive, educational, formal, functional, generative, and many more can be compounded onto linguistics to characterize specific frameworks and approaches. In this brief editorial, we outline the rationale for the notion and the corresponding journal of Pedagogical Linguistics, defining how we see the term in comparison to closely related, and more familiar notions.

Keywords: language education, language pedagogy, language teaching, pedagogical linguistics, second language acquisition, second language classroom

\section{Why Pedagogical Linguistics?}

Linguistics comes in many flavors. Applied, cognitive, descriptive, educational, formal, functional, generative, and many more can be compounded onto linguistics to characterize specific frameworks and approaches. Neuro-, psycho-, socio-, etc. can be prefixed to refer to particular areas of inquiry. This profusion of subfields, approaches, and frameworks is testament to the dynamism of the field. And it is to be expected as language encompasses so many different facets of human behavior, each of which deserves close study in its own right. It is a formal symbolic system which is mentally represented. It is a social semiotic system for construction of identities in interaction. And so on. While such dynamism and diversity in the field are welcome, the connections between these different strands of inquiry are intricate, and, unfortunately, sometimes antagonistic. One might therefore wonder what the contribution of a new compound in the form of Pedagogical Linguistics to this already crowded terminological field will be. In this brief editorial, we outline the rationale for the journal of Pedagogical Linguistics, defining how we see the term in comparison to closely related, and more familiar notions. 
The term is not intended to denote a new subfield of linguistics. Rather, it serves as the point of contact for any and all linguistic research that is pedagogical in orientation. As Dick Hudson points out in his contribution to this first issue, linguistics is fundamentally pedagogical, and it always has been. Whether it is descriptive work in the properties of a language being exploited for developing teaching materials, or ideas about how language is learned informing changes in language teaching methodologies, linguistics has always had an intimate relationship with language pedagogy, and it might therefore be helpful to teach the importance of pedagogical concepts and applications also to our students of linguistics (see Bardovi-Harlig's paper and her suggestions in this context). Even if the relationship has been close, it has not necessarily always been happy. Much discussion has been devoted to tricky distinctions between theory and application, and between linguistics and language teaching, not least by another contributor to this first issue of Pedagogical Linguistics: Henry Widdowson (see for example Widdowson, 2000a, 2000b, 2002, 2020).

Much of this discussion has sought to characterize the field of Applied Linguistics and what distinguishes this as an independent field of applied inquiry within the wider field of linguistics. The area is now well served by its own publications (e.g., Davies \& Elder, 2006; and the journal Applied Linguistics). How do we differentiate Pedagogical Linguistics from Applied Linguistics? Inevitably, there is much overlap and such differences that exist are a matter of degree and emphasis. Nonetheless, the idea of Pedagogical Linguistics should serve to focus attention on the specifically pedagogical. Traditionally, this has been a crucial part of Applied Linguistics, but as the field has matured, it has encompassed a wider range of issues connected to the status of language(s) and linguistics in society and has moved beyond an original focus on matters of learning and teaching to explore questions at the intersection of language, law, politics, and society.

In this context, researchers have established the term Educational Linguistics (see Hult, 2008 for the historical development of this field), and one might wonder how our term Pedagogical Linguistics differs from this branch of Applied Linguistics. Hult (2008:17-18) states that

[t]he individual educational linguist, trained in any number of combinations of [....] relevant areas of study, might have her or his home in a variety of different departments, including anthropology, applied linguistics, area studies, education, English, foreign languages, linguistics, psychology, and sociology. Common to all educational linguists, though, is training in critical thinking of a transdisciplinary nature $[\ldots]$

Given this definition and understanding of an educational linguist, it follows that more sociologically-oriented research areas such as language policy and language 
planning are a crucial part of Educational Linguistics too (see Spolsky, 2005; Hult, 2018). Again, although we acknowledge the importance of exploring these factors, we envisage Pedagogical Linguistics to be more clearly focused on the nature and cognitive underpinnings of language in itself.

So, as the field of Applied Linguistics and the Educational Linguistics branch of this field have matured to become their own independent areas of inquiry, connections to linguistic theory, in the sense of theories which seek to account for the nature of language itself, have perhaps become more strained. Widdowson (2000a, 200ob) has noted that Applied Linguistics can be compared and contrasted to 'linguistics applied. The latter equates the object of study of linguistics with the subject of learning in pedagogy and sees unmediated application from findings from the academic discipline to questions of teaching and learning. Of course, findings from any linguistic framework which carries out research in and on its own terms should require careful consideration and reflection before ideas of applications can be suitably formulated. But the danger of an overly strict separation is that theoretically-oriented linguists see application as something that per se lies outside of their remit, and so don't even attempt to engage in application. And from the applied linguistic perspective, scholars are suspicious of theory and skeptical about any potential moves from theory to application.

Thus, as subfields diverge and go their own way, linguists (applied and theoretical) sometimes end up eyeing each other suspiciously over conceptual divides that have opened up. For example, in a recent exchange in the pages of Applied Linguistics, the potential 'misunderstanding' of generative theory and its relevance to Applied Linguistics was discussed (Slabakova et al., 2014, 2015). This was in turn attacked as an attempt to remain relevant from a field that is "withering" (De Bot, 2015:261). But as De Bot (2015:263-264) also noted, the attempt to reach out in collaboration by Slabakova and colleagues was praiseworthy, though he suggests it will ultimately prove futile as "[m] ost researchers already have enough problems staying up-to-date in their own subfield. Few will take the time (and risk) to switch to a different paradigm while the community that supports their own approach is large enough."

This, we believe, gets to the heart of the problem and suggests why something like Pedagogical Linguistics can contribute to part of a solution. Generative theory, just like any theory of language acquisition, can surely deliver insights relevant for teaching and learning (see papers in Whong et al., 2013 on generative theory; Littlemore, 2009 on an alternative formal approach in terms of cognitive/construction grammar; and the recent collection of papers in Trotzke \& Kupisch, 2020). But, as illustrated in the volumes just cited, discussion of application and pedagogical relevance often remains within particular research communities. And the risk when moving beyond boundaries is that any productive discussion is pre- 
cluded by deeply-held theoretical positions leading to questioning of fundamental principles rather than genuine engagement on questions of pedagogical relevance (as in the Slabakova et al./De Bot exchange). It is then unsurprising that those scholars or educators who have no particular conceptual axe to grind might view linguistic discussion as academic in every sense of the word, and might find it hard to navigate the abstract theoretical issues to get to the core of any potential useful application.

This often results in a research/practice divide that is in fact pointed out by the very same research groups that conduct instruction-oriented classroom research on a theoretical basis. In particular, recent studies have empirically shown that school teachers and other educators refrain from consulting current linguistic research for reasons such as time constraints, insufficient access to online databases, and insufficient knowledge of linguistic terminology (Marsden \& Kasprowicz, 2017; Sato \& Loewen, 2019). Also, these studies have found that many sources that teachers actually do consult and that they think represent proper linguistic research are actually of low quality, according to common standards and measures like the Social Sciences Citation Index, which help define a field of inquiry such as linguistics and language acquisition research. This situation with its potential confusions and ambiguities has already led researchers to conclude that "the findings of academic research are bound to be no less misleading and unreliable than teachers' experience and intuitions" (Medgyes, 2017:509), and that, consequently, there is nothing to gain from bridging the gap between linguistic research and language-pedagogy practitioners.

Of course, disagreement, leading to conceptual and empirical refinement of ideas, is the lifeblood of any field. And such disagreement and refinement carries on daily in academic conferences and in the pages of any number of scholarly publications. For the purposes of pedagogical relevance of linguistics and language acquisition, our contention is that it would be beneficial for this to come about as the result of engagement and constructive mutual criticism in a forum where the pedagogical is foregrounded. This should encourage scholars to consider how their theories need to be mediated to accommodate questions of pedagogy, and it should encourage reflection on 'opposing' models or frameworks and whether and how there are areas of divergence or convergence specifically with respect to pedagogical notions. The very idea of opposition is problematic when viewed from the perspective of language pedagogy and language-teaching practitioners, whose engagement is impacted by the various constraints mentioned above. Pedagogy cannot afford simply to dismiss some aspect of language on a priori theoretical grounds. At some points, and for some purposes, it will make sense to emphasize the pragmatic, social, and cultural facets of a language in pedagogy (see Bardovi-Harlig's contribution in this first issue); at other times, and for other 
purposes, the formal properties of language will be more to the fore (as stated in Hudson's target article). This inherent ecumenism of language pedagogy should help to promote greater engagement between areas of linguistics.

Of course, we continue to encourage disagreement and challenge so that ideas are better honed. But we see Pedagogical Linguistics as offering a point of convergence where all approaches to the nature of language and all approaches to the study of linguistics are welcome to formulate the potential pedagogical import of their research. The pedagogic value of work on linguistics and language acquisition research is something that we can all agree on. However, work emanating from specific subfields might not be immediately accessible, or might appear simply unappealing, to colleagues from neighboring frameworks. By providing a forum which collects theoretically and empirically diverse approaches that share a concern with pedagogy, we hope that the journal can act as a bridge-builder between different areas of linguistics and between linguistic theory and pedagogical application. As for the pedagogical application, the journal will also feature an open-public lay abstract for each research article, which will be specifically targeted at language-teaching practitioners. These extended abstracts will introduce and summarize the insights of each article in a non-technical way and will be published on the OASIS platform for open accessible summaries in language studies $<$ https://oasis-database.org $>$.

However, 'application' in the sense of ideas making the journey from theory to final use in a language classroom is not necessarily the sole overriding goal of Pedagogical Linguistics. It is of fundamental interest in its own right to investigate how language is learned and taught in pedagogical settings, and what this means for both pedagogy and linguistic theory, even in the absence of 'application' Indeed, with respect to application, Larsen-Freeman (2015:274) has observed that considering how research is 'applicable' is perhaps not the best way to proceed; rather, "the most important contribution of research to practice is to challenge teachers to think differently, to experiment with new practices, and to help them make the tacit explicit by cultivating new ways of talking about their practice" (Larsen-Freeman, 2015:274).

So, in addition to any potential uses and applications, the hope is that by engaging with questions of pedagogy across theoretical and conceptual boundaries, we can also more clearly define and refine the assumptions we make about learning and acquisition in a productive way for audiences who might not share the same set of axiomatic beliefs. In so doing, one contributes to key questions at the heart of the study of language in general. 


\section{The contributions}

Pedagogical Linguistics starts off with an issue that contains three target articles that are very fundamental in nature, outlining and defining the field in a way that will hopefully be inspiring to readers:

Richard Hudson: Towards a pedagogical linguistics

Henry Widdowson: Linguistics, language teaching objectives and the language learning process

Kathleen Bardovi-Harlig: Pedagogical linguistics: A view from L2 pragmatics

In addition, we include a first regular article, which exemplifies how theoreticallyinformed experimental research can contribute to our understanding of core phenomena such as tense and aspect, which are central to questions of language acquisition research as well as language teaching:

Amber Dudley \& Roumyana Slabakova: Aspectual contrasts in the English present tense revisited: Exploring the role of input and L1 influence

\section{References}

Davies, A., \& Elder, C. (2006). The handbook of applied linguistics. Malden, MA: Blackwell.

De Bot, K. (2015). Moving where? A reaction to Slabakova et al. (2014). Applied Linguistics, 36 , 261-264. https://doi.org/10.1093/applin/amu074

Hult, F. (2008). The history and development of educational linguistics. In B. Spolsky \& F. Hult (Eds.), Handbook of educational linguistics (pp. 1-10). Oxford: Blackwell. https://doi.org/10.1002/9780470694138.ch2

Hult, F. (2018). Language policy and planning and linguistic landscapes. In J.W. Tollefson \& M. Pérez-Milans (Eds.), Oxford handbook of language policy and planning (pp. 333-351). Oxford: Oxford University Press.

Larsen-Freeman, D. (2015). Research into practice: Grammar learning and teaching. Language Teaching, 48, 263-28o. https://doi.org/10.1017/S0261444814000408

Littlemore, J. (2009). Applying cognitive linguistics to second language learning and teaching. Basingstoke: Palgrave Macmillan. https://doi.org/10.1057/9780230245259

Marsden, E., \& Kasprowicz, R. (2017). Foreign language educators' exposure to research: Reported experiences, exposure via citations, and a proposal for action. The Modern Language Journal, 101, 613-642.

Medgyes, P. (2017). The (ir)relevance of academic research for the language teacher. ELT Journal, 71, 491-498. https://doi.org/10.1093/elt/ccx034

Sato, M., \& Loewen, S. (2019). Do teachers care about research? The research-pedagogy dialogue. ELT Journal, 73, 1-10.

Slabakova, R., Leal, T., \& Liskin-Gasparro, J. (2014). We have moved on: Current concepts and positions in generative SLA. Applied Linguistics, 35, 601-606.

https://doi.org/10.1093/applin/amuo27 
Slabakova, R., Leal, T., \& Liskin-Gasparro, J. (2015). Rumors of UG’s demise have been greatly exaggerated. Applied Linguistics, 36, 265-269. https://doi.org/10.1093/applin/amvoo7

Spolsky, B. (2005). Is language policy applied linguistics? In P. Bruthiaux, D. Atkinson,

W. G. Eggington, W. Grabe \& V. Ramanathan (Eds.), Directions in applied linguistics (pp. 26-36). Clevedon: Multilingual Matters.

Trotzke, A., \& Kupisch, T. (Eds.) (2020). Formal linguistics and language education: New empirical perspectives. Dordrecht: Springer.

Whong, M., Gil, K.H., \& Marsden, H. (Eds.) (2013). Universal grammar and the second language classroom. Dordrecht: Springer. https://doi.org/10.1007/978-94-007-6362-3

Widdowson, H.G. (2000a). Object language and the language subject: On the mediating role of applied linguistics. Annual Review of Applied Linguistics, 20, 21-33. https://doi.org/10.1017/S0267190500200020

Widdowson, H. G. (200ob). On the limitations of linguistics applied. Applied Linguistics, 21, 3-25. https://doi.org/10.1093/applin/21.1.3

Widdowson, H.G. (2002). Language teaching: defining the subject. In H. R. Trappes-Lomax \& G. Ferguson (Eds.), Language in language teacher education (pp. 68-81). Amsterdam: John Benjamins. https://doi.org/10.1075/lllt.4.05wid

Widdowson, H.G. (2020). On the subject of English: The linguistics of language use and learning. Berlin: Mouton de Gruyter.

\section{Addresses for correspondence}

Andreas Trotzke

Fachbereich Linguistik

Universität Konstanz

Universitätsstraße 10

78457 Konstanz

Germany

andreas.trotzke@uni-konstanz.de

Tom Rankin

Zentrum für Fachsprachen und Interkulturelle Kommunikation

Johannes Kepler Universität Linz

Altenberger Straße 69

4040 Linz

Austria

thomas.rankin@jku.at 